\title{
VIDEORRESENHAS DO BOOKTUBE: UMA ANÁLISE DA ORGANIZAÇÃO SOCIORRETÓRICA DESSE GÊNERO
}

\author{
VIDEO REVIEWS OF BOOKTUBE: \\ AN ANALYSIS OF THE SOCIORETORIC ORGANIZATION OF THIS GENRE
}

\author{
Júlio Araújo* \\ Francisco Rogiellyson da Silva Andrade** \\ Janyele Gadelha de Lima***
}

\section{RESUMO}

Este artigo analisa a resenha de livro no âmbito da rede social YouTube, considerando as estratégias de distribuição de informações nas resenhas publicadas nesse ambiente virtual. Teoricamente, apoiamo-nos, principalmente, no que se concerne ao processo de reelaboração de gêneros nas redes sociais (ARAÚJO, 2016). Além disso, partimos do instrumental analítico chamado Create a Research Space (CARS), proposto, inicialmente, por Swales (1984), para o estudo da organização de introduções de artigos científicos, posteriormente utilizado por Motta-Roth (1995) e outros autores para o estudo da resenha acadêmica. Partindo de uma metodologia de cunho etnográfico, reunimos 10 resenhas produzidas por usuários desse ambiente virtual, os chamados booktubers. A análise dos dados nos mostra que, apesar de muitos moves e subfunções que compõem a resenha acadêmica se manterem nessa realização do gênero, novas unidades retóricas, porém, aparecem nas resenhas, o que demonstrou a necessidade da reelaboração da sua organização retórica para contemplar o ato de resenhar no YouTube.

Palavras-chave: reelaborações de gêneros; BookTube; videorresenha.

\section{ABSTRACT}

In this paper, we examine book reviews that are published on the social media YouTube, considering the strategies used for the distribution of information. The reflection on the process of genre re-elaboration on social medias (ARAÚJO, 2016) is our main theoretical support. In addition, we also use the Create a Research Space (CARS) model, which was initially proposed by Swales (1984) to explain and describe the organizational pattern of writing the introduction to scholarly research studies, and posteriorly used by Motta-Roth (1995) and other researchers to analyze the organizational pattern of writing academic reviews. Using a methodology with ethnographical features, we gathered 10 book reviews elaborated by booktubers, which are the users of this virtual environment. Analysis we made shows that, despite the many moves e sub-functions in the writing of academic reviews also are present in the book reviews published on YouTube, new rhetorical unities appear indicating the necessity of re-elaboration for the organizational pattern of writing that genre in order to complete the act of reviewing a book on YouTube. Keywords: genre re-elaboration; BookTube; video reviews.

\section{CONSIDERAÇÕES INICIAIS}

O ato de resenhar é uma prática discursiva, comumente escrita, por meio da qual alguém tece comentários críticos acerca de um livro lido. Sousa (2012), com base no que propôs Araújo (2006), defende que a resenha forma uma constelação de gêneros, já que, por meio do ato de resenhar, podemos chegar à resenha de música, à resenha de teatro, à resenha de cinema e à resenha de ballet, por exemplo. Segundo essa compreensão, o ato de resenhar não é exatamente um gênero, mas uma prática discursiva complexa, que, por meio das muitas ações nela envolvidas, podese chegar a vários tipos de resenhas. Assim, por meio da perspectiva da constelação de gêneros proposta por Araújo $(2016$; 2021), aquele autor demarca que as resenhas, em decorrência dos diferentes domínios em que se constituem, formam gêneros distintos, pois organizam-se heterogeneamente.

Nessa medida, a depender da esfera de atividade de seus produtores e leitores, a resenha pode estar vinculada a vários discursos, como o acadêmico (MOTTA-ROTH, 1995; ARAÚJO, 1996; 2009; BEZERRA, 2009) e o

\footnotetext{
* Professor e pesquisador no Programa de Pós-Graduação em Linguística e no Departamento de Letras Vernáculas da Universidade Federal do Ceará, Fortaleza, CE, Brasil. araujo@ufc.br

Orcid: https://orcid.org/0000-0001-7399-3769.

** Doutorando em Linguística pelo Programa de Pós-Graduação em Linguística da Universidade Federal do Ceará, Fortaleza, CE, Brasil. rogiellyson@alu.ufc.br

Orcid: https://orcid.org/0000-0002-2585-1878.

***Doutoranda em Letras pelo Programa de Pós-Graduação em Literatura Comparada da Universidade Federal do Ceará, Fortaleza, CE, Brasil. janyeleg@gmail.com

Orcid: https://orcid.org/0000-0002-0523-7598
} 
jornalístico (SOUSA, 2012; COSTA; COSTA, 2014). Mas não apenas aos domínios discursivos exemplificados se circunscreve o ato de resenhar, haja vista, atualmente, essa prática social ser atualizada na dinâmica das redes sociais, espaço para onde confluem vários domínios de discurso. São muitos os exemplos que podemos citar aqui e que ilustram bem o modo pelo qual a prática discursiva de resenhar se atualiza nas redes sociais. A exemplo disso, Araújo et al. (2018) perceberam que as resenhas escritas na rede social Skoob configuram-se com uma organização retórica diferente daquela tradicionalmente preconizada no discurso acadêmico, justamente por, nesse ambiente, uma nova dinâmica discursiva se instaurar entre os integrantes da comunidade discursiva dos resenhistas digitais (ARAÚJO; SOUSA; CAVALCANTI, 2020), o que evidenciou uma reelaboração do gênero resenha acadêmica nas redes sociais.

O BookTube, sendo também um desses notáveis exemplos, é uma comunidade de canais do YouTube em que os usuários, os chamados booktubers, compartilham suas resenhas orais acerca dos livros que leram, entre outras atividades envolvendo o mundo literário. O BookTube hoje possui um número muito expressivo de canais brasileiros cujos usuários, para dar sustentação verbal às suas necessidades enunciativas, utilizam a resenha de livro como um dos gêneros mais praticados entre eles. Como as resenhas são audiovisuais, doravante, chamaremos esse gênero de videorresenha, pois, conforme perceberam Lima et al. (2018) em estudo preliminar acerca das resenhas realizadas nesse ambiente virtual, parece haver um processo de reelaboração, tal como percebeu o estudo de Araújo et al. (2018) e de Araújo, Sousa e Cavalcanti (2020) no que se refere às resenhas veiculadas na rede social Skoob.

Diante disso, neste trabalho, interessamo-nos pela análise da videorresenha de livro existente na ambiência discursiva do YouTube, considerando não somente que esse gênero se centra em semioses verbo-visuais, mas também que sua organização retórico-discursiva se engendra de maneira singular em relação às diferentes práticas discursivas em que se pratica o ato de resenhar, o que nos faz hipotetizar que há o processo de reelaboração do gênero resenha acadêmica no BookTube.

Com esse intento, o presente artigo se organiza da seguinte forma: 1 - apresentamos o conceito de reelaboração de gêneros e o modelo Create a Research Space construído inicialmente para a composição retórica da introdução de artigos científicos e que, posteriormente, foi adaptado por Motta-Roth (1995) para ser aplicado ao estudo da resenha acadêmica, adaptação essa que usaremos como ponto de partida para a investigação das videorresenhas; 2 - explicamos como funciona e como se dão as interações na rede social BookTube 3 - descrevemos nossos passos metodológicos; 4 - analisamos nosso corpus de pesquisa; e 5 - apresentamos nossas considerações acerca da análise.

\section{O FENÔMENO DA REELABORAÇÃO DE GÊNEROS}

Araújo (2016) e colaboradores compreendem reelaborações de gêneros como o processo pelo qual os gêneros discursivos, em função dos usos, transformam-se entre si, muitas vezes, gerando/fazendo emergir novos gêneros. Conforme esses estudiosos, os gêneros que organizam as práticas discursivas nas redes sociais apontam para um absortivo movimento de reelaboração criadora que transita em um continuum entre a estandardização e a emergência, cujo protagonismo do sujeito pode ser compreendido em graus de maior ou menor intervenção.

Conforme propõe Araújo (2016), o processo de reelaboração criadora e inovadora de gêneros discursivos nas redes sociais está associado à relativa liberdade de criação proporcionada por esses espaços virtuais que permitem aos usuários experimentarem diferentes técnicas de produção de textos híbridos que acontecem por meio das atividades de recortar/copiar e colar, próprias das tecnologias digitais.

No caso das resenhas praticadas pelos adeptos do BookTube, acreditamos que esse processo é mutante e criativo, como a própria língua, de maneira que, em função disso, as pessoas não param de criar uma nova estandardização, decorrente da "vida" social que existe nesses ambientes. Navas (2010) designa essas práticas de remix e masbup e diz que elas estão na base daquilo que ele define como cultura remix. Assim, podemos dizer que as redes sociais são ambientes que permitem a produção e o consumo da cultura remix, a partir da qual os sujeitos reelaboram diferentes tipos de mesclas de gêneros para organizar as práticas discursivas entre eles.

Com base nessa ideia, apresentamos, a seguir, o modelo CARS e sua aplicação para o gênero resenha, noções a partir das quais embasamos a análise dos dados desta pesquisa. 


\section{MODELO CARS E O GÊNERO RESENHA ACADÊMICA}

O modelo Create a Research Space (CARS), elaborado por Swales (1984), propõe que os gêneros, principalmente os acadêmicos, se constroem a partir de uma organização retórica que lhes permite atingir seus propósitos comunicativos. Tal modelo melhor se adéqua à análise de gêneros acadêmicos, pois estes são resultantes de uma rotina mais padronizada de construção de textos.

Nessa perspectiva, Swales (1984) mostra que os gêneros são formados por moves e subfunções (ou steps). Os primeiros se referem às unidades retóricas que compõem os textos; os segundos são subunidades que permitem a composição retórica de cada move. Assim, entende-se que cada move possui um propósito comunicativo próprio, o qual permite que o gênero atinja seu objetivo maior. Nessa proposta, portanto, entende-se que os gêneros, como entidades relativamente estáveis (BAKHTIN, 1997), possuem uma arquitetura que lhes subjaz, de maneira a proporcionar o alcance de seus propósitos comunicativos. Para aplicar sua teorização, Swales (1984) analisou introduções de artigos acadêmicos. Adeptos dessa concepção aplicam a proposta desse autor a outros gêneros, a fim de perceber como se dá a relativa estabilidade retórica dos textos em cada domínio sócio-discursivo.

Um exemplo disso é o estudo de Motta-Roth (1995), que consiste na aplicação do modelo CARS à análise da resenha acadêmica. Tal estudo aqui nos interessa por permitir que entendamos a composição rotineira desse gênero, ou seja, a arquitetura textual que, na proposta da autora, engendra-o, de modo a fazermos comparações com as videorresenhas que analisaremos.

A partir de sua análise, Motta-Roth (1995) elabora o seguinte quadro como esquema de composição retórica do gênero resenha acadêmica:

Move 1

Subfunção 1

Subfunção 2

Subfunção 3

Subfunção 4

Subfunção 5

Move 2

Subfunção 6

Subfunção 7

Subfunção 8

Move 3

Subfunção 9

\section{Move 4}

Subfunção $10 \mathrm{~A}$

Subfunção 10 B

\section{INTRODUZIR O LIVRO}

Definindo o tópico geral do livro

e/ou

Informando sobre leitores em potencial

e/ou

Informando sobre o autor

e/ou

Fazendo generalizações sobre o tópico

e/ou

Inserindo o livro na área

SUMARIAR O LIVRO

Provendo uma visão geral da organização do livro

e/ou

Apresentando o tópico de cada capítulo

e/ou

Citando material extratextual

DESTACAR PARTES DO LIVRO

Provendo avaliação direcionada

PROVER UMA AVALIAÇÃO FINAL DO LIVRO

Recomendando/desqualificando completamente o livro

ou

Recomendando o livro apesar de indicar limitações

Figura 1. Descrição esquemática da arquitetura sociorretórica das resenhas acadêmicas

Fonte: Motta-Roth, 1995, p. 141.

Motta-Roth (1995), como ilustrado na figura 1, entende que a resenha se constrói a partir de 4 moves, cada um deles com subfunções próprias, que auxiliam aqueles a se comporem. Assim, com base na rotina retórica dos textos 
analisados pela autora, as resenhas iniciam-se pela apresentação geral do livro resenhado. Nesse move, o resenhista pode fazer uso de até 5 subfunções, pois, em sua resenha, ele pode definir o assunto central do livro (subfunção 1), pode indicar o público alvo para aquele texto (subfunção 2), apresentar o autor da obra em análise, bem como suas credenciais (subfunção 3), além de promover generalizações sobre o assunto do livro (subfunção 4) e/ou, ainda, determinar a área do saber em que tal texto pode ser enquadrado (subfunção 5).

Após isso, no move 2, as resenhas apresentam uma sumarização do livro, com o fito de apresentar suas ideias gerais e organização textual. Esse move é composto por 3 subfunções, uma vez que o resenhista pode tratar do livro de uma maneira mais geral (subfunção 6), ou a partir de cada capítulo ou seção da obra (subfunção 7). Além disso, pode trazer para a resenha material extratextual, como imagens, citações, entre outros recursos (subfunção 8).

No terceiro move, o resenhista normalmente destaca partes da obra resenhada, de maneira a apresentar seus pontos principais de colaboração científica e conceitual para a área de referência. É possível, ainda, que essa avaliação nem sempre seja positiva, de modo a apresentar pontos que podem ser considerados falhos e problemáticos no desenvolvimento do raciocínio. Como há um destaque para determinadas partes do livro a serem avaliadas, o resenhista faz uso da única subfunção presente nesse move, a 9.

Por fim, no move 4, o resenhista apresenta uma avaliação final do livro em análise. Para isso, ele pode empregar duas subfunções: se recomendar ou desqualificar completamente o livro, temos a subfunção $10 \mathrm{~A}_{\text {; }}$ porém, se indicar o livro, mas com algumas ressalvas, temos a subfunção 10B.

Como o modelo de Motta-Roth (1995) foi criado para a análise de resenhas de livros no suporte impresso, as quais circulam na ambiência acadêmica, é lícito pensar que, talvez, faça-se necessário realizar adaptações nesse modelo, a fim de contemplar os movimentos retóricos encontrados nas videorresenhas do BookTube, uma vez que as condições de produção nesse ambiente virtual são outras.

Obviamente, com base em Hyland (2000), entendemos que, conforme inclusive preconiza o modelo de Motta-Roth (1995), mesmo as resenhas acadêmicas, a depender da disciplina à qual se vinculam, apresentam certa heterogeneidade retórica, em virtude das culturas disciplinares que organizam os discursos dessas áreas. Se consideramos essa hipótese, podemos pensar que, num discurso já distante do acadêmico, tal como o do BookTube, a organização retórica das videorresenhas, ainda que se possa basear na proposta de Mota-Roth (1995), apresenta uma nova estandardização, a qual se vincula às necessidades enunciativas de seus praticantes.

Com base nessas considerações teóricas, a seguir, apresentamos a descrição da metodologia que viabilizou o processo de construção e análise das videorresenhas que compuseram nosso corpus de estudo.

\section{METODOLOGIA}

Foi no cenário do BookTube, rede social voltada para a distribuição e para o compartilhamento digital de vídeos, que surgiu nosso corpus. Estes são uma comunidade de canais literários, isto é, compõem uma comunidade literária dentro do YouTube, formadas por booktubers, sujeitos que gravam vídeos falando sobre livros, dando dicas de lançamentos, respondendo perguntas feitas pelos inscritos (as chamadas tags) e elaborando resenhas desses livros. Muitos desses canais são famosos e contam com mais de 200 mil inscritos, o que ratifica a importância de entendermos como essa nova maneira de indicar leituras se organiza retoricamente e, dessa forma, promove interações. Toda essa euforia chamou a atenção das editoras, autores e livrarias, que formaram parcerias com alguns canais. A partir disso, os booktubers recebem gratuitamente os livros que serão ou foram lançados recentemente pela editora que lhes patrocina, a fim de que, tendo uma videorresenha feita por um booktuber famoso, o livro seja melhor divulgado e as vendas subam.

Instigados por esse novo ambiente em que circulam as resenhas e levados a investigar como se dá o processo de reelaboração desse gênero nesse ambiente, selecionamos 10 videorresenhas produzidas por booktubers, a fim de melhor analisá-las e estudá-las a partir do modelo CARS proposto por Motta-Roth (1995) para análise da resenha acadêmica.

Ressaltamos que, para manter protegida a identidade dos sujeitos produtores das resenhas, em nossa análise, elas foram numeradas e codificadas. Com isso, o código VR1, por exemplo, é utilizado para nos referirmos à primeira videorresenha por nós separada para este estudo. Além disso, a reunião e posterior análise das resenhas se deu a partir da leitura e assinatura do termo de consentimento livre e esclarecido pelos booktubers criadores dos canais analisados. 
Como bem defende Araújo (2006, 2009, 2016, 2021), para que os estudos sobre linguagem e tecnologia tenham solidez metodológica, é importante que o pesquisador se coloque no ambiente em que está inserido seu corpus de análise, o que significa dizer que este seja um usuário das tecnologias e um utente dos contratos sociais entre os membros da comunidade discursiva de seu interesse. Entre as possibilidades de pesquisa qualitativa, a etnografia é uma alternativa produtiva, pois permite ao pesquisador estudar o seu objeto no contexto cultural em que ele acontece. À luz dessa perspectiva, podemos dizer que,

se a interpretação está construindo uma leitura do que acontece, então divorciá-la do que acontece [...] é divorciá-la das suas aplicações e torná-la vazia. Uma boa interpretação de qualquer coisa - um poema, uma pessoa, uma estória - leva-nos ao cerne do que nos propomos interpretar (GEERTZ, [1973] 1989, p. 28).

Dessa forma, os dados desta pesquisa foram gerados por meio da participação ativa e direta dos pesquisadores na rede social BookTube. Com o corpus devidamente construído, realizou-se a análise. Diante disso, assistimos às videorresenhas do BookTube, procurando, primeiramente, perceber que unidades retóricas se mantinham em relação ao modelo de organização retórica elaborado por Motta-Roth (1995) para a resenha acadêmica. Após isso, analisamos unidades não previstas para este tipo de resenha, mas que, recorrentemente, aconteciam nas videorresenhas, o que nos fez construir, com base no conceito de reelaboração de gêneros, um novo quadro de moves e subfunções que caracterizasse a composição sociorretórica do gênero videorresenha nesse ambiente virtual de interação. Apresentamos nossa análise no tópico a seguir.

\section{A ORGANIZAÇÃO SOCIORRETÓRICA DAS VIDEORRESENHAS DO BOOKTUBE}

A partir das análises do corpus, percebemos que há uma proeminente reelaboração do gênero resenha acadêmica, seja do ponto de vista da linguagem seja do ponto de vista da arquitetura sociorretórica que engendra o gênero. Conforme teoriza Bakhtin (1997), os gêneros são delineados a partir das esferas discursivas a que se vinculam. Nessa conjuntura, percebe-se que, ao migrar da esfera acadêmica para a literária, ainda que se perceba certa estabilidade do gênero com aqueles com que se irmana em sua teia constelar (ARAÚJO, 2021), algo de diferente torna-o singular.

Como salientamos anteriormente, ainda que os sujeitos produtores reconheçam que produzem resenhas de livros, o que já os faz serem praticantes do ato de resenhar, o fato de suas resenhas se realizarem na modalidade oral aponta para um processo de reelaboração do gênero, o que nos fez chamar as resenhas dessa rede social de videorresenhas. Essa modalidade oral, nesse ambiente de interação, é eivada de sentidos figurados e gírias, distanciando-se de um registro linguístico rebuscado e/ou formal comum em resenhas acadêmicas, como se pode ver na transcrição a seguir:

Então, é um livro que faz os jovens aí pensarem melhor nas coisas, no preconceito bobo que as pessoas têm às vezes.... Faz a gente realmente imaginar como nós somos capazes de fazer um mundo melhor... (Fonte: transcrição da VR1; dados da pesquisa (2017).

A partir da fala de VR1, percebe-se o caráter mais informal que a resenha no BookTube adquire. Segundo teoriza Maingueneau (2001), a língua é um instrumento de construção do ethos, entendido pelo autor como a maneira por meio da qual

[...] revela-se a personalidade do enunciador. [...] São os traços de caráter que o orador deve mostrar ao auditório (pouco importa sua sinceridade) para causar boa impressão: são os ares que assume ao se apresentar. [...] O orador enuncia uma informação, e ao mesmo tempo diz: eu sou isto, eu não sou aquilo (MAINGUENEAU, 2001, p. 98).

Com base no que afirma Maingueneau (2001), podemos dizer que a escolha por uma modalidade mais informal de uso da língua tem a função precípua de atrair e aproximar o videorresenhista do público-alvo de seus vídeos. Outra evidência disso, também na fala de VR1, ocorre quando a autora se apresenta da seguinte maneira:

Oi, oi, gente. Aqui é a [apelido da videorresenhista], do Nuvem Literária.

(Fonte: transcrição da VR1; dados da pesquisa (2017)).

Ao se apresentar apenas por meio de seu apelido, a videorresenhista afirma-se mais próxima de seu público, na tentativa de desverticalizar a relação entre si e seus seguidores, ratificando um ethos mais despojado na interação com seus interlocutores. Ora, se consideramos a teorização de Hyland (2000), as disciplinas acadêmicas se constroem em 
torno de uma verticalização do conhecimento, de maneira que autores com titulações mais altas e know-bow na área à qual se vinculam têm credenciais maiores em relação aos demais para discursar acerca de determinadas temáticas. Num ambiente como o do BookTube, porém, em que os videorresenhistas necessitam garantir audiência, inclusive para terem um retorno financeiro da própria plataforma do YouTube, é necessário manter uma horizontalidade entre estes e seu público, o que, entre outras maneiras, ocorre através de usos mais informais da língua. Outra demonstração disso, que encontramos em todas as videorresenhas, é o fato de, quando se apresentam, os booktubers estabelecerem uma espécie de conversa, com elementos fáticos próprios de um diálogo.

Oi, oi, gente. (Fonte: transcrição da VR1; dados da pesquisa (2017)).

Oi, gente. Tudo bem? (Fonte: transcrição da VR3; dados da pesquisa (2017)).

Olá, pessoal, tudo bom? (Fonte: transcrição da VR4; dados da pesquisa (2017)).

Fala, galera! Tudo bom com vocês? (Fonte: transcrição da VR5; dados da pesquisa (2017)).

Como veremos à frente, a apresentação é um move que se constrói nas videorresenhas do BookTube, mas, nos exemplos, queremos evidenciar esse contato conversacional, quase íntimo, inclinado, que o videorresenhista procura estabelecer com o público de seu canal, evidência que muito demonstra a reelaboração da resenha nessa rede social, pois aponta para o caráter de conversa que se estabelece entre os sujeitos da interação, mesmo que ambos não se comuniquem presencial e instantaneamente. Ao encontro disso, VR5, ao dizer "Fala, galera!", assim como VR1, além de estabelecer essa conversa próxima com o público, também constrói um ethos de ser uma pessoa mais despojada, que usa uma linguagem mais próxima do cotidiano, tal como se estivesse conversando com amigos próximos. Esse comportamento pode atrair um maior público, o que, no contexto do BookTube, é extremamente importante, uma vez que, ao ter muitos seguidores, alguns booktubers são mais cotados pelas editoras para fazerem resenhas de livros recémpublicados, sendo, portanto, patrocinados.

No que se refere à análise retórica das videorresenhas, quando aplicamos o modelo elaborado por Motta-Roth (1995), encontramos o resultado expresso no quadro a seguir.

Quadro 1. Análise das videorresenhas do BookTube a partir do modelo elaborado por Motta-Roth (1995)

\begin{tabular}{|c|c|}
\hline & Videorresenhas \\
\hline MOVE 1 & VR1, VR2, VR3, VR4, VR5, VR6, VR7, VR8, VR9, VR10 \\
\hline Subfunção 1 & VR1, VR4, VR5, VR6, VR8 \\
\hline Subfunção 2 & VR1, VR3, VR4, VR5, VR7, VR8, VR9, VR10 \\
\hline Subfunção 3 & VR5, VR6, VR7, VR8, VR9, VR10 \\
\hline Subfunção 4 & VR1, VR4, VR5, VR6, VR7, VR8, VR9 \\
\hline Subfunção 5 & VR6, VR7, VR8, VR9 \\
\hline MOVE 2 & VR9 \\
\hline Subfunção 6 & VR2, VR6, VR7, VR8, VR9, VR10 \\
\hline Subfunção 7 & \\
\hline Subfunção 8 & \\
\hline MOVE 3 & VR1, VR2, VR3, VR4, VR5, VR6, VR7, VR8, VR9, VR10 \\
\hline Subfunção 9 & VR1, VR8, VR9 \\
\hline MOVE 4 & VR2, VR3, VR4, VR5, VR6, VR7, VR10 \\
\hline Subfunção 10 & \\
\hline Subfunção 10B & \\
\hline
\end{tabular}

Fonte: Construção própria.

A partir dessa evidência, é perceptível que todos os moves e subfunções propostos por Motta-Roth (1995) para a resenha acadêmica também se realizam nas videorresenhas, o que significa que os booktubers, de fato, inseremse no ato de resenhar e, por isso, participam do universo constelar referente a essa prática discursiva. No entanto, em nossa análise, muitos momentos dos vídeos ficaram sem classificação se levássemos em consideração somente 
o modelo da autora, uma vez que sua proposta não abarcava as especificidades do ato de resenhar na ambiência do BookTube, o que aponta, mais uma vez, para o conceito de constelação de gêneros tal como pensado por Araújo (2021), se lembrarmos que, embora irmanados, cada gênero, no universo constelar de que faz parte, possui luz própria, isto é, atende a necessidades enunciativas específicas a determinadas práticas de linguagem.

Em decorrência disso, sentimos a necessidade de construir um novo modelo, o qual busca dar conta da explicitação dos movimentos retóricos que compõem a videorresenha. É importante ressaltar, como já deve ter sido inferido, que nossa intenção não é perceber as distâncias entre a resenha acadêmica e a videorresenha, mas sim analisar como as unidades retóricas que lhes compõem se arquitetam no continuum de gêneros que compõem o ato de resenhar, tal como formulado por Sousa (2012). Nossa reformulação é apresentada no quadro a seguir.

Quadro 2. Modelo de organização retórica das videorresenhas do BookTube

\begin{tabular}{|c|c|}
\hline $\begin{array}{c}\text { Move } 1 \text { - } \\
\text { Saudação inicial }\end{array}$ & $\begin{array}{l}\text { Subfunção } 1 \text { - Saudando o público, apresentando o canal e o tema do vídeo: VR1, VR2, VR3, } \\
\text { VR4, VR5, VR6, VR7, VR8, VR9, VR10; } \\
\text { Subfunção } 2 \text { - Rodando a vinheta do canal: VR3, VR4, VR5, VR6, VR7, VR8, VR9, VR10; }\end{array}$ \\
\hline $\begin{array}{l}\text { Move } 2- \\
\text { Introduzir } \\
\text { o livro }\end{array}$ & $\begin{array}{l}\text { Subfunção } 3 \text { - Definindo o tópico geral do livro: VR1, VR2, VR3, VR4, VR5, VR6, VR7, VR8, } \\
\text { VR9, VR10; } \\
\text { Subfunção } 4 \text { - Informando sobre leitores em potencial: VR1, VR4, VR6, VR8; } \\
\text { Subfunção } 5 \text { - Informando sobre o autor: VR1, VR3, VR5, VR7, VR8, VR9, VR1; } \\
\text { Subfunção } 6 \text { - Fazendo generalizações sobre o tópico: VR5, VR6, VR7, VR8, VR9, VR10; } \\
\text { Subfunção } 7 \text { - Inserindo o livro na área: VR1, VR4, VR5, VR6, VR7, VR8, VR9; }\end{array}$ \\
\hline $\begin{array}{l}\text { Move } 3- \\
\text { Sumariar } \\
\text { o livro }\end{array}$ & $\begin{array}{l}\text { Subfunção } 8 \text { - Promovendo uma visão geral da organização do livro: VR6, VR7, VR8, VR9; } \\
\text { Subfunção } 9 \text { - Apresentando o tópico de cada capítulo: VR9; } \\
\text { Subfunção } 10 \text { - Citando material extratextual: VR2, VR3, VR4, VR5, VR6, VR7, VR8, VR9, } \\
\text { VR10; }\end{array}$ \\
\hline $\begin{array}{l}\text { Move } 4 \text { - } \\
\text { Destacar } \\
\text { partes do livro }\end{array}$ & $\begin{array}{l}\text { Subfunção } 11 \text { - Promovendo avaliação direcionada: VR1, VR2, VR3, VR4, VR5, VR6, VR7, } \\
\text { VR8, VR9, VR10; } \\
\text { Subfunção } 12 \text { - Ler trechos do livro: VR7, VR9; }\end{array}$ \\
\hline $\begin{array}{l}\text { Move } 5 \text { - } \\
\text { Avaliação } \\
\text { final do livro }\end{array}$ & $\begin{array}{l}\text { Subfunção 13A - Recomendando/Desqualificando completamente o livro: VR1, VR8, VR9; } \\
\text { Subfunção 13B - Recomendando o livro apesar de indicar limitações: VR2, VR4, VR5, VR6, } \\
\text { VR7, VR10; } \\
\text { Subfunção } 14 \text { - Dar estrelas: VR2, VR3, VR9; }\end{array}$ \\
\hline $\begin{array}{l}\text { Move } 6 \text { - } \\
\text { Despedida }\end{array}$ & $\begin{array}{l}\text { Subfunção } 15 \text { - Despedindo-se do público: VR1, VR2, VR3, VR4, VR5, VR6, VR7, VR8, } \\
\text { VR9, VR10 } \\
\text { Subfunção } 16 \text { - Solicitando interação nos comentários: VR2, VR3, VR4, VR5, VR9, } \\
\text { Subfunção } 17 \text { - Requisitando likes, joinhas e inscrição no canal: VR1, VR2, VR3, VR4, VR5, } \\
\text { VR6, VR7, VR8, VR10; } \\
\text { Subfunção } 18 \text { - Disponibilizar links para compras: VR6, VR8, VR10. }\end{array}$ \\
\hline
\end{tabular}

Fonte: Construção própria.

Com base no Quadro 2, percebe-se que, no BookTube, surgem novos moves e subfunções não previstos no modelo de Motta-Roth (1995) para a resenha acadêmica. Quanto a isso, o move 1, que se refere à apresentação do canal, já demonstra a reelaboração do gênero pois é realizado por todas as videorresenhas reunidas, o que evidencia, com base em Araújo (2016), o caráter de estabilização que esse move adquiriu, ainda que não existisse no modelo mais canônico das resenhas acadêmicas. Esse move tem a função de, à medida que apresenta o canal, popularizá-lo, em decorrência de ser o momento em que ocorre sua publicização. Ele cria uma espécie de logomarca do canal, a qual fica sendo a etiqueta pela qual é reconhecido. Ao longo de sua composição retórica, encontramos as subfunções 1, de apresentar o canal, o booktuber e o tema do vídeo, e a subfunção 2, de transmitir a vinheta do canal. 
Quadro 3. Evidências da subfunção 1 nas videorresenhas do BookTube

\begin{tabular}{|c|l|}
\hline $\begin{array}{c}\text { Videor- } \\
\text { resenha }\end{array}$ & Subfunção 1 - Saudando o público, apresentando o canal e o tema do vídeo \\
\hline VR3 & $\begin{array}{l}\text { Oi, gente. Tudo bem? Aqui é a } * * *, \text { do Lendo e Comentando, e hoje eu vou falar sobre um livro que eu li } \\
\text { recentemente. }\end{array}$ \\
\hline VR4 & $\begin{array}{l}\text { Olá, pessoal, tudo bom? Eu sou a ***, você está no canal Literature-se, e hoje o vídeo é sobre esse livro } \\
\text { aqui \{olha para o livro\}, a Biblioteca Invisível, que se você também gostar, né, da premissa dele e estiver } \\
\text { pela área de Campinas, Unicamp, que é minha faculdade, na segunda-feira, fique de olho até o final do } \\
\text { vídeo que eu vou dizer como você pode aí tentar encontrar um exemplarzinho de graça pela Unicamp. }\end{array}$ \\
\hline VR5 & $\begin{array}{l}\text { Fala, galera. Tudo bom com vocês? Sejam bem-vindos a mais um vídeo do Geek Freak. E hoje eu tô aqui } \\
\text { com vocês pra falar tudo que eu achei dessa leitura maravilhosa que foi Objetos Cortantes. }\end{array}$ \\
\hline
\end{tabular}

Fonte: dados da pesquisa (2017).

Tal como se pode comprovar por meio do quadro 2, de fato, existe um move que se refere à apresentação do canal, no qual há um momento em que o videorresenhista se apresenta. Essa apresentação serve, como vimos há pouco, para iniciar o contato com o público e trazer à tona efeitos de uma interação mais horizontalizada.

Além dessa subfunção, há também, no move 1, a vinheta do canal, subfunção realizada em 8 das resenhas analisadas. Tal fenômeno ocorre pelo fato de muitos videorresenhistas serem patrocinados por editoras para produzirem suas avaliações críticas. A partir do momento em que apresentam o canal, os autores constroem legitimidade em torno de si, estabelecendo credenciais e fama entre os pares para fazer suas videorresenhas, pois, como dissemos, a vinheta é uma maneira de marcar os expectadores através da logomarca utilizada pelo booktuber.

Além disso, outras duas subfunções aparecem nas videorresenhas. A primeira delas, enquadrada no move 3, é a de número 12, que se refere à leitura de trechos do livro.

\section{Quadro 4. Evidências da subfunção 12 nas videorresenhas do BookTube}

\begin{tabular}{|c|l|}
\hline $\begin{array}{c}\text { Videor- } \\
\text { resenha }\end{array}$ & Subfunção 12 - Ler trechos do livro \\
\hline VR7 & $\begin{array}{l}\text { Eu vou ler um trechinho, né, do momento em que eles abrem a porta pra tirar o caixão da casa, e é } \\
\text { impressionante, gente, vamo lá: "Primeiro procuram torcer a tranca que parece soldada às oxidadas } \\
\text { dobradiças, mas não conseguem movê-la". [...] "Os homens se tornam brutalmente visíveis, como um } \\
\text { relâmpago ao meio-dia e cambaleiam." }\end{array}$ \\
\hline VR9 & $\begin{array}{l}{[\ldots] \text { eu achei a escrita [...] maravilhosa. [...] eu até marquei [mostrando o livro] uma passagem aqui }} \\
\text { do livro [...] e agora eu vou ler pra vocês: "Ela, muito tímida, não dava o menor sinal de que desejava } \\
\text { prolongar a conversa. Ficávamos ali encerrados em oito ou dez palavras a cada encontro. Eu pegava cada } \\
\text { palavra que ela dizia e guardava em um estojo de veludo na minha memória. Decorava o tom, o som, o } \\
\text { jeito de falar. Sua voz era uma música que nenhum instrumento era capaz de reproduzir. Eu, apaixonado, } \\
\text { tentava imaginar milhões de significados por trás de qualquer coisa que ela dissesse." }\end{array}$ \\
\hline
\end{tabular}

Fonte: dados da pesquisa (2017).

Como se vê no Quadro 4, os videorresenhistas se valem da leitura de trechos da obra, subfunção que inferimos ter duas funções: 1 - seduzir o público a ler a obra, despertando sua curiosidade pelo desenrolar do enredo, tal como se vê na VR7; e 2 - validar e exemplificar a avaliação realizada pelo booktuber, como se pode comprovar na VR9.

No que se refere ao move de avaliação, existe, no BookTube, uma décima quarta subfunção, que se refere ao ato de dar estrelas, como se pode ver no quadro a seguir. 
Quadro 5. Evidências da subfunção 14 nas videorresenhas do BookTube

\begin{tabular}{|c|l|}
\hline $\begin{array}{c}\text { Videor- } \\
\text { resenha }\end{array}$ & Subfunção 14 - Dar estrelas \\
\hline VR2 & Não, se fosse pra dar 5 estrelas, eu daria 4 estrelas pra esse livro. \\
\hline VR3 & $\begin{array}{l}\text { Enfim, eu gostei muito desse livro, eu dei } 4 \text { estrelas pra ele no Skoob. Eu tirei uma estrela dele porque eu } \\
\text { queria que algumas tivessem sido mais trabalhadas, tivessem sido mais exploradas }\end{array}$ \\
\hline VR9 & Eu dei cinco estrelas pra ele [mostrando o livro] obviamente, marquei como favorito. Foi perfeito! \\
\hline
\end{tabular}

Fonte: dados da pesquisa (2017).

Tal como evidencia o Quadro 5, faz parte da avaliação dos livros videorresenhados esse ato de fornecer estrelas, que é uma espécie de medição numérica da qualidade da obra. Hyland (2009, p. 89, tradução nossa') diz que, "embora toda escrita acadêmica seja avaliadora de alguma forma, as resenhas de livro o são explicitamente", o que ratifica a ideia de que o ato de resenhar é eminentemente avaliativo. Essa avaliação, no caso da estilização do gênero videorresenha, dá-se a partir de critérios subjetivos, a exemplo da emoção que o videorresenhista diz ter sentido ao ler o livro de que fala.

Essa forma de avaliar, como discutido anteriormente, se distancia da avaliação construída no âmbito acadêmico que, conforme analisa Bezerra (2009), se vale de critérios validados cientificamente para avaliar uma determinada obra, dando primazia a argumentos de autoridade na elaboração do texto. Porém, construindo a avaliação a partir de argumentos mais subjetivos, fica evidente que o público que consome videorresenhas interessa-se por uma avaliação que ressalte aspectos mais afetivos.

Ainda no que se refere a isso, algo relevante a destacar é que essa ideia de atribuir estrelas, como se pode inferir da fala da VR3, é uma função migrada de outra rede social que também se apresenta como espaço para resenhas de livros: o Skoob. Nessa rede social, também voltada para o compartilhamento de leituras entre os usuários, conforme perceberam Araújo et al. (2018), após avaliar um livro, o resenhista pode oferecer de 1 até 5 estrelas à obra, a depender de seu gosto, além de ainda ser possível favoritá-lo, que significa torná-lo um dos livros mais importantes para aquele leitor. Percebemos, assim, que tanto a linguagem quanto a forma de interagir com o público no BookTube se inspiram em funções existentes no Skoob. Isso é importante em função de aquela rede social ter emergido posteriormente a esta. Assim, necessário se faz migrar algumas das funções da primeira, a fim de seduzir seus adeptos.

Assim como é necessário apresentar-se, como visto no move 1, também é necessário, nas videorresenhas, haver um momento dedicado à despedida, que compõe o move 6, constituído por 4 subfunções. A primeira delas, despedir-se do público, é realizada por todas as videorresenhas que estudamos.

Quadro 6. Evidências da subfunção 15 nas videorresenhas do BookTube

\begin{tabular}{|c|l|}
\hline $\begin{array}{c}\text { Videor- } \\
\text { resenha }\end{array}$ & Subfunção 15 - Despedindo-se do público \\
\hline VR3 & Enfim, por hoje é isso, obrigado por terem assistido até aqui, um beijo e tchau, até o próximo vídeo. \\
\hline VR10 & $\begin{array}{l}\text { Então é isso, gente. Espero que vocês tenham gostado, espero que vocês se interessem por esse livro, que } \\
\text { vocês deem uma chance, porque é um livro muito legal. [...] Um beijo [gesto do beijo] e até o próximo } \\
\text { vídeo. }\end{array}$ \\
\hline
\end{tabular}

Fonte: dados da pesquisa (2017).

A subfunção 15 diz respeito à despedida do videorresenhista. Nada mais natural de acontecer, se consideramos que o contato que este estabelece com seu interlocutor é o mais horizontal possível. Numa conversa, sempre é necessário que os sujeitos se despeçam; se assim o é, para manter essa interação horizontal, faz-se relevante que haja um momento para a despedida. O que chama nossa atenção na construção dessa subfunção é, tal como se pode perceber pela transcrição, que os booktubers utilizam gestos para despedir-se. Isso nos remete a algo intrínseco às videorresenhas: a multissemiose própria dos gêneros da ambiência dos multiletramentos (LEMKE, 2016).

1. Texto original: "While all academic writing is evaluative in some way, book reviews are explicitly so" (HYLAND, 2009, p. 89). 
Por vídeo, os produtores podem utilizar-se das inúmeras possibilidades da linguagem verbal oral (informalidade, entonação, marcadores discursivos), mas também de efeitos de luz e de focagem/desfocagem, imagens estáticas e/ou em movimento, gestualidades, expressões corporais e faciais, efeitos sonoros (ROJO, MOURA, 2019), o que dá aos textos o caráter interativo e multissemiótico, chamando a atenção do público e, portanto, atribuindo legitimidade ao canal. Nessa perspectiva, diferentemente da resenha acadêmica, cujo produtor precisa ter segurança teórica, solidez argumentativa e dominar a linguagem acadêmica, o videorresenhista precisa saber utilizar diferentes modos semióticos de interação para se legitimar entre os seus pares. Tal evidência mostra as diferentes maneiras de construção de autoria nas práticas de linguagem da ambiência digital.

Além da subfunção 15, há também a 16, que dá ao booktuber a possibilidade de solicitar comentários do público.

Quadro 7. Evidências da subfunção 16 nas videorresenhas do BookTube

\begin{tabular}{|c|l|}
\hline $\begin{array}{c}\text { Videor- } \\
\text { resenha }\end{array}$ & Subfunção 16 - Solicitando interação nos comentários \\
\hline VR4 & $\begin{array}{l}\text { Quem quiser que eu resenhe mais livros é só me pedir aqui nos comentários e ... eu também tô pensando } \\
\text { em fazer resenha de filme, então é só pedir também. Hãm, os comentários que tiverem bem mais likes, } \\
\text { ou os dois que tiverem mais likes, eu pergunto depois no twitter qual vocês preferem, e o que vocês } \\
\text { preferirem eu resenho. }\end{array}$ \\
\hline VR5 & $\begin{array}{l}\text { Se vocês já leram esse livro, comenta aqui embaixo o que vocês acharam, se você concorda com o que eu } \\
\text { disse, se você tem alguma coisa a acrescentar, vamos discutir um pouquinho sobre ele. }\end{array}$ \\
\hline
\end{tabular}

Fonte: dados da pesquisa (2017).

Como a interação entre videorresenhista e público não se dá face a face, os comentários são uma possibilidade de os pares trocarem ideias, opiniões e sugestões entre si. Essa ferramenta permite que o booktuber se mostre como alguém dedicado a seu público e que com ele, de fato, estabeleça uma relação horizontal, além de evidenciar que aquele está aberto a opiniões e contra-argumentos trazidos por este. A partir disso, mais fama e melhores credenciais terá o videorresenhista.

Outra subfunção que compõe o move 6 é a requisição de likes/joinhas e de inscrições no canal. Likes ou joinhas são ferramentas do YouTube a partir das quais o público avalia o vídeo assistido. Caso o público avalie positivamente, deve clicar no ícone que indicia isso (dedo polegar apontado para $\left.\mathrm{cima}^{2}\right)_{\text {; }}$ do contrário, há o ícone que avalia o vídeo negativamente (dedo polegar apontado para baixo³). Além disso, existe, ainda, a possibilidade de os usuários se inscreverem nos canais de que mais gostam, ferramenta que informa ao usuário inscrito sempre que um novo vídeo é publicado no canal. Das videorresenhas por nós compiladas, apenas a VR9 não realizou essa subfunção.

A subfunção 6 é importante porque a quantidade de likes nos vídeos e de inscritos em um canal evidencia o sucesso que ele faz dentro da comunidade, o que também chama a atenção dos patrocinadores. Assim, ao fazer essas requisições, o booktuber demonstra humildade e simpatia com seu público e, também, lembra-o de fazer uma boa avaliação do que assistiu, de maneira a fidelizar seus expectadores e atrair possíveis e/ou novos patrocínios.

Portanto, a solicitação de avaliações e inscrições, assim como os próprios comentários, permite que o canal fique famoso no âmbito do Youtube e do próprio BookTube; quanto mais usuários inscritos no canal, maior visibilidade este terá, mais apoio financeiro receberá da plataforma, e, por conseguinte, um maior número de patrocinadores se interessará por solicitar uma videorresenha.

Por fim, ainda no move 6, existe, também, a subfunção 18, por meio da qual os videorresenhistas disponibilizam, seja no próprio vídeo seja na descrição $0^{4}$ do vídeo, links para compra do livro videorresenhado.

4. A descrição é um espaço abaixo da janela em que corre o vídeo, onde o seu autor pode resumir o conteúdo que veicula ou fornecer informações adicionais. 
Quadro 8. Evidências da subfunção 18 nas videorresenhas do BookTube

\begin{tabular}{|c|l|}
\hline $\begin{array}{c}\text { Videor- } \\
\text { resenha }\end{array}$ & Subfunção 18 - Solicitando interação nos comentários \\
\hline VR6 & $\begin{array}{l}\text { Aqui na descrição do vídeo tem o link pra quem quiser comprar o seu próprio [mostra o livro] exemplar } \\
\text { lindão de O menino que desenhava monstros. Comprando por esse link, eu ganho uma porcentagem piquitita } \\
\text { [faz o gesto com a mão] do valor total da compra, e isso ajuda tanto o canal quanto o blog [link com } \\
\text { recomendação de outro canal aparece na tela] a crescerem. }\end{array}$ \\
\hline VR8 & $\begin{array}{l}\text { Se você quiser ler Cinder, quê que você tem que fazer? Por favor? [faz o gesto de juntar as mãos] Comprar } \\
\text { no meu link, que vai tá aqui embaixo [apontando para baixo]. Vai lá e compra o do link aqui de baixo } \\
\text { [apontando para baixo]. Tem um link genérico [aparecem, na tela, os ícones das redes sociais do autor do } \\
\text { canal], você entra no site da Amazon, compra o que você quiser, tá bom? }\end{array}$ \\
\hline
\end{tabular}

Fonte: dados da pesquisa (2017).

Essa subfunção foi encontrada somente em três exemplares do corpus, pois ela, comumente, só ocorre em canais com maior visibilidade, patrocinados por editoras e/ou por lojas virtuais que querem vender os livros. A partir de um link específico, as editoras têm a possibilidade de perceber se as videorresenhas, de fato, estão promovendo uma propaganda eficaz do livro e, portanto, alavancando as vendas.

Obviamente, inclusive com base em Swales (1984), a rede de moves que compõem a arquitetura sociorretórica dos gêneros é sempre seguida por aqueles que os pratica, porque os sujeitos compartilham entre si os propósitos comunicativos veiculados por sua comunidade discursiva e têm em mente que, para isso, precisam desse esquema retórico. Ainda conforme afirma Swales (1984), as subfunções, por seu turno, baseiam-se na relação e/ou, isto é, são facultativas no engendramento retórico dos moves, de maneira que nem todas elas são, efetivamente, realizadas no texto. Isso porque, mesmo que apresentando uma estruturação organizacional prototípica, os textos são entidades dinâmicas. Inclusive, com base na análise da reelaboração das resenhas na rede social Skoob empreendida por Araújo et al. (2018) e por Araújo, Sousa e Cavalcanti (2020), as subfunções são as unidades mais propensas à reelaboração, justamente em razão de seu dinamismo. As videorresenhas, como um gênero emergente, são evidências disso.

A seguir, apresentamos nossas considerações acerca da análise que aqui empreendemos.

\section{CONSIDERAÇÕES FINAIS}

A partir da análise, percebemos que o modelo de Motta-Roth (1995), de fato, é reelaborado se se tem o fito de contemplar a videorresenha do BookTube. Nessa medida, seja do ponto de vista da linguagem, que se aproxima de uma modalidade mais informal, seja do ponto de vista da construção retórica, que se adequa às necessidades enunciativas do BookTube, as videorresenhas apontam para o fenômeno da reelaboração do gênero resenha acadêmica, uma vez que, mesmo entendendo que produzem uma resenha, os produtores desse gênero o reelaboram, de modo a estabelecer uma relação mais horizontal com o público e, nesse intuito, perfazem uma reconstrução retórica do gênero.

Queremos dizer com isso que as videorresenhas da rede social BookTube se engendram no ato discursivo de resenhar e, portanto, fazem parte da constelação dos gêneros próprios dessa prática discursiva, por isso mesmo apresentam especificidades sociorretóricas próprias. Ainda que alguns dos moves e subfunções que emergem nesse gênero não sejam praticados em todos os textos que conseguimos analisar, outras unidades retóricas já aparecem como estáveis, o que significa dizer que as videorresenhas, como a própria língua, apresentam uma emergência própria dos textos virtuais, no sentido de apresentarem uma arquitetura textual que, ao mesmo tempo que se altera, também se solidifica, demonstrando a dinamicidade e a plasticidade que arquitetam a organização retórica e as necessidades enunciativas que perfazem a interação humana pela linguagem em tempos de digitalidades.

\section{REFERÊNCIAS}

ARAÚJO, A. D. Lexical signalling: a study of unspeci c-nouns in book reviews. 1996. Tese (Doutorado em Linguística Aplicada) - Universidade Federal de Santa Catarina, Florianópolis. 
ARAÚJO, A. D. O gênero resenha acadêmica: organização retórica e sinalização lexical. In: BIASI-RODRIGUES, B.; ARAÚJO, J. C.; SOUSA, S. C. T. (Org.). Gêneros textuais e comunidades discursivas: um diálogo com John Swales. Belo Horizonte: Autêntica Editora, 2009, p. 77-93

ARAÚJO. J. Os chats: uma constelação de gêneros na Internet. Tese (Doutorado em Linguística). Fortaleza: Universidade Federal do Ceará, 2006.

ARAÚJO, J. Reelaborações de gêneros em redes sociais. In. ARAÚJO, J.; LEFFA, V. Redes sociais e ensino de línguas: o que temos de aprender? São Paulo: Parábola Editorial, 2016, p. 49-64.

ARAÚJO, J. Constelação de gêneros: a construção de um conceito. São Paulo: Parábola, 2021. ARAÚJO, J. C. et al. O ato de resenhar no Skoob. Letras em Revista, Teresina, v. 9, n. 01, jun. 2018, p. 107-118. Disponível em: <https://ojs.uespi.br/index.php/ler/article/view/132>. Acesso em: 03 mar. 2020.

ARAÚ́JO, J.; SOUSA, M. M. N.; CAVALCANTI, J. M. Comunidade discursiva e redes sociais: os resenhadores do Skoob. Revista Intercâmbio, v. 45, n. 1, p. 28-51, 2020.

BAKHTIN, M. Estética da criação verbal. Tradução de Maria Ermantina Galvão G. Pereira. 2. ed. São Paulo: Martins Fontes, 1997.

BEZERRA, B. G. A resenha acadêmica em uso por autores proficientes e iniciantes. In: BIASI-RODRIGUES, B.; ARAÚUO, J. C.; SOUSA, S. C. T. (Org.). Gêneros textuais e comunidades discursivas: um diálogo com John Swales. Belo Horizonte: Autêntica Editora, 2009, p. 95-115.

COSTA, R. R.; COSTA, S. M. Corpos em campo: performance, visibilidade e impermeabilidade na apresentação do self de jogadores de futebol no Instagram. Linguagem \& Ensino, Pelotas, v.17, n.3, p.677-704, set./dez. 2014.

GEERTZ, C. A interpretação das culturas. Rio de Janeiro: LTC, 1989.

HYLAND, K. Disciplines and discourses: social interactions in the construction of knowledge. Pearson Education Limited, 2000.

HYLAND, K. Academic discourse: English in a Global Context. London: Continuum, 2009.

LEMKE, J. L. Letramento metamidiático: transformando significados e mídias. Trabalbos em Linguística Aplicada, Campinas, v. 49, n. 2, p. 455-479, 2016. Disponível em: https://periodicos.sbu.unicamp.br/ojs/index.php/tla/article/view/8645275. Acesso em: 26 jun. 2021.

LIMA, J. G. et al. Reelaboração do gênero resenha no YouTube. In: LIMA, J. A. de. et al. Atas do IV Encontro Internacional de Jovens Investigadores - JOIN 2018. Açores: Universidade dos Açores, 2018, p. 520-529.

MAingueneAu, D. Análise de textos de comunicação. Tradução de Cecília P. de Souza-e-Silva e Décio Rocha. São Paulo: Cortez, 2001.

MOTTA-ROTH, D. Rhetorical Features and Disciplinary Cultures: a genre-based study of academic book reviews in linguistics, chemistry and economics. 1995. 356 f. Tese (Doutorado em Linguística Aplicada) - Universidade Federal de Santa Catarina, Florianópolis, 1995.

NAVAS, E. Regressive and Reflexive Mashups in Sampling Culture. In: SONVILLA-WEISS, S. (Ed.). Mashup Cultures. Wien; New York: Springer, 2010. p. 157-177.

ROJO, R.; MOURA, E. Letramentos, Mídias, Linguagens. São Paulo: Parábola, 2019.

SOUSA, S. C. T. de. Gênero textual e comunidade jornalística. São Paulo: Blucer Acadêmico, 2012.

SWALES, J. M. Research Into the Structure of Introductions to Journal Articles and its Application to the Teaching of Academic Writing. In: WILLIAMS, R.; SWALES, J; KIRKMAN, J. Common Ground: shared interests in ESP and communication studies. ELT Documents 117, 1984.

Recebido: $16 / 1 / 2021$

Aceito: 24/6/2021

Publicado: 26/8/2021 